\title{
Metaplastic breast carcinoma with upper limb gangrene
}

This article was published in the following Dove Press journal:

Breast Cancer - Targets and Therapy

2 May 2017

Number of times this article has been viewed

\author{
Reynu Rajan' \\ Norlia Abdullah' \\ Nik Muhd Aslan Abdullah ${ }^{2}$ \\ Abdul Yazid Mohd Kassim ${ }^{3}$ \\ 'Department of Surgery, ${ }^{2}$ Department \\ of Oncology and Radiotherapy, \\ ${ }^{3}$ Department of Orthopedic Surgery \\ and Traumatology, Universiti \\ Kebangsaan Malaysia Medical Centre, \\ Kuala Lumpur (UKMMC), Malaysia
}

\begin{abstract}
Metaplastic breast carcinomas (MBCs) are rapidly growing tumors with histological heterogeneity, and triple negative receptor status. The aim of this case report is to highlight a case of advanced MBC with axillary artery infiltration leading to gangrene of the ipsilateral upper limb, in a young woman.
\end{abstract}

Keywords: metaplastic breast carcinoma, axillary artery infiltration, gangrene

\section{Case presentation}

A 22-year-old nulliparous Chinese woman with no significant family history of cancer presented to a private medical center with a painless $5 \mathrm{~cm}$ swelling in the left breast. The swelling, which was first noticed 3 months earlier, increased in size gradually. There was no associated nipple discharge or swelling elsewhere. Core biopsy of the swelling confirmed an infiltrating ductal carcinoma with triple negative receptor status for ER, PR, and HER2 receptors. Computed tomography (CT) of the thorax, abdomen, and pelvis was negative for distant metastasis. By then, 2 weeks had passed since she first presented with her complaints. Following discussion between the attending surgeons, the patient, and her family, the decision to proceed with neoadjuvant chemotherapy immediately, was made. Two weeks into her neoadjuvant chemotherapy, she complained that the left breast mass had significantly increased in size from the initial $5 \mathrm{~cm}$ to $10 \mathrm{~cm}$ in diameter. She also developed a swelling in the left axilla that was clinically consistent with that of an axillary lymph node. Fine needle aspiration cytology of the left axillary lymph node was reported to be a metastatic carcinoma. A decision was made to proceed with left mastectomy and axillary clearance. Histopathology examination of the $14 \mathrm{~cm}$ by $12 \mathrm{~cm}$ left breast mass was conclusive for high-grade metaplastic breast carcinoma - spindle cell subtype, triple negative receptor status. All 12 excised axillary lymph nodes were positive for metastases. Six weeks following surgery, she underwent adjuvant chemotherapy. She defaulted follow-up soon after completion of chemotherapy and underwent Traditional Chinese Medication instead, despite advice regarding potential spread of the disease, and grave prognosis should that occur.

Four months later, she presented to a district hospital with complaints of pain over the left chest wall and inability to move her left upper limb. On examination, a large fungating mass with a necrotic patch was seen at her left chest wall, extending into the axilla. The tumor had infiltrated the anterior chest wall and was even seen over the 
posterior chest wall. The left upper limb was cold, pale, and mottled with patchy areas of necrosis. The brachial artery, radial artery, and ulnar artery were not palpable. Doppler signals were negative for all three arteries as well. Capillary refill time was significantly prolonged. There was no motor or sensory function in the left upper limb. A right breast lump was also noted during examination, measuring approximately $6 \mathrm{~cm}$ by $5 \mathrm{~cm}$ with enlarged ipsilateral axillary lymph nodes. Core biopsy of the right breast lump revealed similar histopathology and immunohistochemistry findings as the left breast lump, supporting the suspicion of a metastatic disease, rather than a separate entity.

$\mathrm{CT}$ of the thorax and abdomen was negative for distant metastases. CT angiogram was not performed, as the patient and family did not agree for her to undergo this invasive investigation. The patient was advised to have another round of palliative chemotherapy and debulking surgery, including a left forequarter amputation. She denied all modalities of intervention. She was given regular subcutaneous morphine and fentanyl patches for analgesia, and her wounds were dressed regularly. The left upper limb tissue gradually became waxy and soft. The flesh over the limb also began to spontaneously separate from the underlying bone, exposing parts of the humerus. The patient eventually requested amputation of the left upper limb, as it was becoming increasingly difficult for her family and nurses to take care of the truncal lesions with the rotting flesh and fragile, non-functioning limb getting in the way. The amputation at the site of the exposed left humerus was performed under intravenous sedation by an experienced orthopedic consultant. The patient succumbed 2 weeks later, slightly more than 6 months from the onset of the disease (Figures 1 and 2). The next of kin has provided written consent for publication of this case report and the accompanying images.

\section{Discussion}

The World Health Organization has recognized metaplastic breast carcinoma (MBC) as a unique pathological entity. ${ }^{1-6}$ $\mathrm{MBC}$ accounts for less than $1 \%$ of invasive breast carcinomas, with the mean age at presentation of 50 years. The tumor is usually large, with axillary lymph node metastases in $25 \%$ of cases. Fifty percent of cases develop local or distant spread within 5 years, with lung and bone metastases, similar to a sarcoma. ${ }^{7,8}$ Shahrun et al ${ }^{9}$ reported six cases that developed tumor recurrence within a year of diagnosis. Immunohistochemistry with broad cytokeratin panel is the best tool to diagnose $\mathrm{MBC} .{ }^{10-12} \mathrm{MBC}$ has poor response to neoadjuvant chemotherapy; surgery is the primary management. ${ }^{8}$ There is no difference in overall survival between patients undergoing

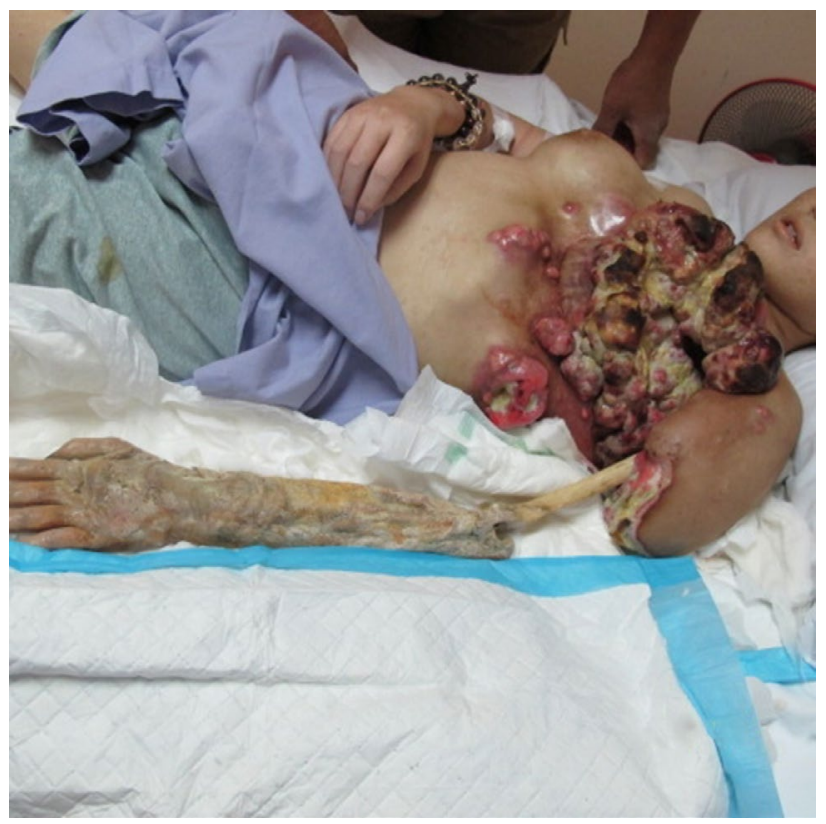

Figure I Cancer on the trunk with left humerus exposed and gangrenous arm.

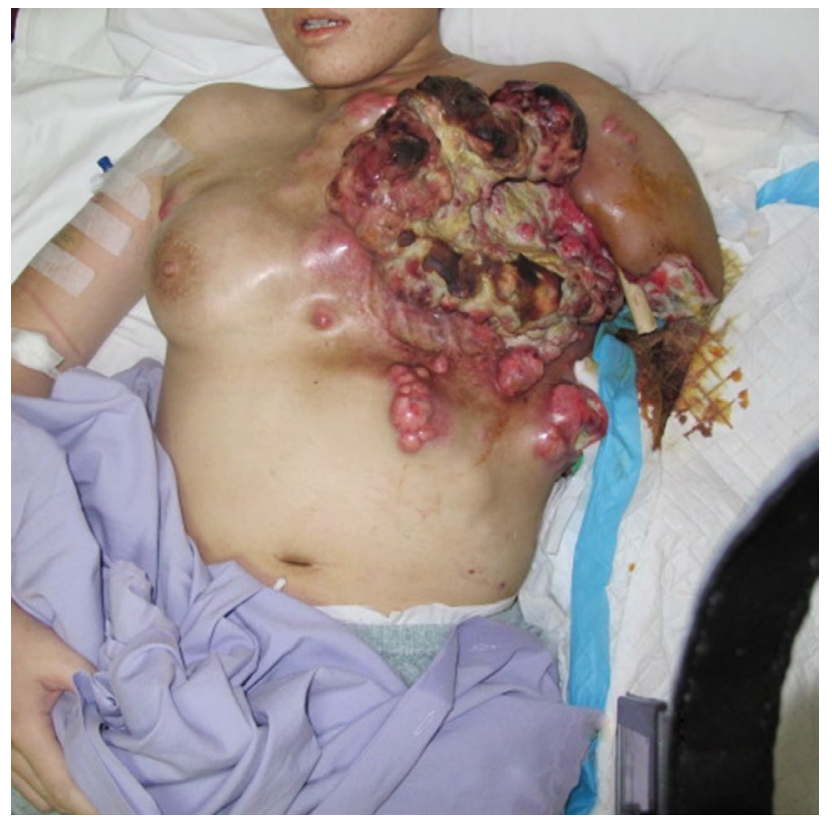

Figure 2 Left humerus post-midshaft amputation.

mastectomy or breast conserving surgery. ${ }^{13} \mathrm{MBCs}$ frequently express EGFR, and have been shown to demonstrate positive response toward targeted therapy. ${ }^{14,15}$ Adjuvant radiotherapy has also been reported to improve overall survival. ${ }^{16}$

\section{Conclusion}

Based on our literature review, this is the youngest, and the first case of metaplastic breast carcinoma with extensive angioinvasion leading to upper limb gangrene. In a multi-ethnic country such as Malaysia, traditional medication and alterna- 
tive therapy is still favored by some over modern medicine, due to deep-rooted cultural beliefs. Such practices, when unregulated, may deny patients of timely access to proper health care, derail them from reality, and dampen the prognosis of salvageable cases. Having said that, much remains unknown regarding this rare subtype of invasive breast cancer. Future direction should be geared toward development of targeted, systemic therapy with improved clinical outcomes.

\section{Author contributions}

Norlia Abdullah conceived the idea to report this case, was the primary consultant managing this case, provided the photos, reviewed and edited the write-up. Reynu Rajan wrote the case report and did the literature review. Nik Muhd Aslan Abdullah managed the case and provided the oncological advice. Abdul Yazid Mohd Kassim managed the case and provided the orthopedic advice. All authors contributed toward data analysis, drafting and revising the paper and agree to be accountable for all aspects of the work.

\section{Disclosure}

The authors report no conflicts of interest in this work.

\section{References}

1. Tavassoli FA, Devilee P, editors. Pathology \& Genetics Tumours of the Breast and Female Genital Organs. Lyon, IARC Press; 2003.

2. Wargotz ES, Norris HJ. Metaplastic carcinomas of the breast: I. Matrixproducing carcinoma. Hum Pathol. 1989;20(7):628-635.

3. Wargotz ES, Deos PH, Norris HJ. Metaplastic carcinomas of the breast: II. Spindle cell carcinoma. Hum Pathol. 1989;20(8):732-740.
4. Wargotz ES, Norris HJ. Metaplastic carcinomas of the breast: III Carcinosarcoma. Cancer. 1989;64(7):1490-1499.

5. Wargotz ES, Norris HJ. Metaplastic carcinomas of the breast: IV. Squamous cell carcinoma of ductal origin. Cancer. 1990;65(2):272-276.

6. Wargotz ES, Norris HJ. Metaplastic carcinomas of the breast: V. Metaplastic carcinoma of the breast with osteoclastic giant cells. Hum Pathol. 1990;21(11):1142-1150.

7. Günhan-Bilgen, Memiş A, Ustün EE, Zekioglu O, Ozdemir N. Metaplastic carcinoma of the breast: clinical, mammographic, and sonographic findings with histopathologic correlation. AJR Am J Roentgenol. 2002;178(6):1421-1425.

8. Luini A, Aguilar M, Gatti G. Metaplastic carcinoma of the breast, an unusual disease with worse prognosis: the experience of the European Institute of Oncology and review of the literature. Breast Cancer Res Treat. 2007;101(3):349-353.

9. Shahrun NS, Rohaizak M, Naqiyah I, Nurismah MI. Metaplastic breast carcinomas: a report of six cases. Medicine \& Health. 2009;4(2): $127-132$.

10. Lui PC, Tse GM, Tan PH, et al. Fine-needle aspiration cytology of metaplastic carcinoma of the breast. J Clin Pathol. 2007;60(5):529-533.

11. Adem C, Reynolds C, Adlakha H, Roche PC, Nascimento AG. Wide spectrum screening keratin as a marker of metaplastic spindle cell carcinoma of the breast: an immunohistochemical study of 24 patients. Histopathology. 2002;40(6):556-562.

12. Leibl S, Gogg-Kammerer M, Sommersacher A, Denk H, Moinfar F Metaplastic breast carcinomas: are they of myoepithelial differentiation?: immunohistochemical profile of the sarcomatoid subtype using novel myoepithelial markers. Am J Surg Pathol. 2005;29(3): 347-353.

13. Dave G, Cosmatos H, Do T, Lodin K, Varshney D. Metaplastic carcinoma of the breast: a retrospective review. Int J Radiat Oncol Biol Phys. 2006;64(3):771-775.

14. Leibl S, Moinfar F. Metaplastic breast carcinomas are negative for Her-2 but frequently express EGFR (Her-1): potential relevance to adjuvant treatment with EGFR tyrosine kinase inhibitors? J Clin Pathol. 2005;58(7):700-704.

15. Dancey JE, Friedlin B. Targeting epidermal growth factor receptor--are we missing the mark? Lancet. 2003;362(9377):62-64.

16. Tseng WH, Martinez SR. Metaplastic breast cancer: to radiate or not to radiate? Ann Surg Oncol. 2011;18(1)94-103.
Breast Cancer - Targets and Therapy

\section{Publish your work in this journal}

Breast Cancer - Targets and Therapy is an international, peerreviewed open access journal focusing on breast cancer research, identification of therapeutic targets and the optimal use of preventative and integrated treatment interventions to achieve improved outcomes, enhanced survival and quality of life for the cancer patient.

\section{Dovepress}

The manuscript management system is completely online and includes a very quick and fair peer-review system, which is all easy to use. Visit http://www.dovepress.com/testimonials.php to read real quotes from published authors. 